\title{
Postmodernity and a hypertensive patient: rescuing value from nihilism
}

\author{
Sam Smith Warrington, Cheshire
}

\begin{abstract}
Much of postmodern philosophy questions the assumptions of Modernity, that period in the history of the Western world since the Enlightment. These assumptions are that truth is discoverable through human reason; that certain knowledge is possible; and furthermore, that such knowledge will provide a basis for the ineluctable progress of Mankind. The Enlightenment project is underwritten by the conviction that knowledge gained through the scientific method is secure. In so far as biomedicine inherits these assumptions it becomes fair game for postmodern deconstruction. Today, perhaps more than ever, plural values compete, and contradictory approaches to health, for instance, garner support and aquire supremacy through consumer choice and media manipulation rather than evidence-based science. Many doctors feel a tension between meeting the needs of the patient face to face, and working towards the broader health needs of the public at large. But if the very foundations of medical science are questioned, by patients, or by doctors themselves, wherein lies the value of their work? This paper examines the issues that the anti-foundationalist thrust of postmodernism raises, in the light of a case of mild hypertension. The strict application of medical protocol, derived from a nomothetic, statistical perspective, seems unlikely to furnish value in the treatment of an individual. The anything goes, consumerist approach, however, fares no better. The author argues that whilst value cannot depend on any rationally predetermined parameters, it can be rescued, and emerges from the process of the meeting with the patient.

(Fournal of Medical Ethics 1998;24:25-31)
\end{abstract}

Keywords: Bioethics; value; professional-patient relationship; postmodernism

On a good day, or at least some part of a good day, I am in no doubt that my interaction with patients has been of value. I take this as a fact of my working life. On a bad day, I wonder if any of it is worthwhile. Sometimes I wonder what the patients make of it all. Perhaps it depends upon a point of view. Or does it?
Marion Jordan, forty-five, curly-haired and pretty, wife to Tony and mother of Alex and Stuart, busy tourist guide, and daughter of Joseph who died of a heart attack when only forty-six waits to have her blood pressure checked. Three times this week her blood pressure has been higher than it should be - although she cannot think what she has done - and if it is high today she must take more of those tablets. Tony will worry and interrogate her about what happened. Her name is called. She has never met this doctor - surely too young to be a doctor - but, amazingly, her blood pressure, so the doctor smilingly announces, is normal. Marion cannot quite understand why this should be, but she smiles back. She is relieved and grateful - even though she has to keep taking the tablets; has to because her father died young; has to because she might have a stroke. She leaves feeling much better.

Such an account is, I know, a fiction. But it is based on an encounter my trainee reported after a recent morning surgery. It is only an anecdote, but I have read that anecdotes, vignettes, stories, or more fashionably, narratives, form a legitimate part of the exchange of medical knowledge and opinion among doctors. ${ }^{1}$ Granted, this anecdote is narrated as if from the patient's point of view. It is an account, none the less, of a particular example of a sort of consultation that does, indeed, happen. One of a kind. Just as Marion is a patient of the hypertensive kind. She is the sort of patient who might die before her time if not medically treated and supervised. Of course, I have no idea when Marion's appointed time will be. But from a statistical point of view, she is the sort of person who, at birth, might have expected to live seventyeight years or so and, having survived to forty-five, to live to seventy-nine - were she not also the sort of person whose father died before his time, and whose blood pressure is raised. I shall return to some of the implications of this point of view later.

What of nihilism, value and Postmodernity? Perhaps I could start with a brief genealogy, to use a Nietzschean term, of Postmodernity without committing myself to a definition of what it is exactly. 


\section{From Modernity to Postmodernity}

In 1619 Descartes, in search of sure knowledge, radically separates mind and body. Certainty is born of doubt. In 1628 William Harvey publishes the results of many years' study of the heart and the circulation of blood. The seat of love and courage becomes a pump. John Graunt, in 1662, counts births and deaths. Health becomes public. In 1666, Sir Isaac Newton places a prism in the path of a ray of light and the rainbow becomes a spectrum. The Enlightenment, in a blinding flash of disenchantment, vanquishes Providence, ordained of God, and ushers in Progress, ordained by Reason.

A hundred years earlier the dualism of Descartes is prefigured in the Mona Lisa's smile which, detaching itself from the surrounding landscape, turns within. ${ }^{2}$ Martin Luther, nailing his ninety-five theses to the church door at Wittenberg, proclaims a new relationship between Man, the Church, and God. Soon after, Copernicus casts Earth into outer space forever disrupting the order of things. A century of doubt, denied by reactive theological bigotry, accelerates the growth of renaissance humanistic individualism, and paves the way for the secularisation of commerce and scientific knowledge. As the Enlightenment dawns, Reason and Science increasingly legitimate the authority of the State and the power of the Church begins to wane. The Western world enters Modernity.

Science, capitalism and burgeoning technology forge an industrial landscape. All is progress. There are no mysteries immune to understanding; no obstacles to a better world that cannot be overcome. Immanuel Kant ensnares morality with a categorical imperative having rational thought alone as its justification. Slavery is abolished, democracy thrives. And yet the Age of Modernity bears the seeds of its own deconstruction.

\section{Romantic utopianism}

The miraculous advances of the centuries of Enlightenment have a darker side, and have always been subject to criticism. By the end of the nineteenth century the clouds of disillusionment are gathering. Industrial manufacture incubates industrial disease, not just of man and woman but of the living earth itself. Karl Marx discerns the alienation of the labourer from the fruits of his labour, now valued for exchange rather than utility. From under the cloak of the valorised war of class against class, a romantic utopianism peeps. Max Weber recoils from an envisioned sarcophagus of progressive rationalisation bound by increasing bureaucratic power. Magic is driven from the world emptying "the haunted air, t色 gnomed mine". ${ }^{3}$

But rational thought, itself the product of newly disembodied mind, steadfastly proclain the path to a truth founded in scientific knowedge, and embodied in technological progre John Keats, surgeon turned poet, mourns the clipping of an angel's wings and the unweaving of a rainbow. But even such an eloquent protest caA not prevent rationality's ultimate and obsceme apotheosis, little more than a century later, in te death camps of the Nazis. "Arbeit macht Frei" Friedrich Nietzsche, ${ }^{4}$ prophet of dreaded nihilisige, observer of the decline of human values, sees $M$ am weakened by Christian self-effacement. Unable $\mathbb{P}$ replace the loss of faith in God's founding authof ity with a comparably substantial faith in human knowledge, he hints that Man might yet fird salvation could he but recognise and fulfil the will to power, and so become Ubermensch.

\section{Nemesis}

The dreams of the Enlightenment founder in the aftermath of two world wars. The aspiration of progress to a better world for all, underwritten rational human thought, is irredeemably tarnished by the threat of nuclear destruction and loongipg ecological catastrophe. Thomas Kuhn deliveฆs body blow to the pretensions of science itself, ${ }^{5}$ and Michel Foucault declares that knowledge $\frac{0}{\mathrm{TS}}$ power, and truth merely resides in discourse. ${ }^{6} \mathrm{FaGt}$ and value collapse into one another. Even the altruistic endeavour of medicine is avowed by Friedson only to subserve the profession's lust for power which monopolises the infrastructure well as the definitions of health and illness. ${ }^{7} \mathrm{Mc}$ eown pricks medical hubris by showing that medicine has little to do with health anyway. ${ }^{8}$ And Ivan Illich prophesies nemesis through the counter-productive medicalisation of culture. ${ }^{9}$

Reality, once more, becomes unknowable. Truth, says Wittgenstein, resides in the shared use of language and not in a real world present human senses. ${ }^{10}$ For Jaques Derrida, words are bet arbitrary signifiers whose reference slips over whit they signify, gaining only an uncertain sense via metonymy and metaphor. There may be a regh world out there, but we can know it only through language; and language is an abstract system $\overline{8} f$ signifiers which assert both identity and differenee at the same time. Meaning is always deferred, and though it emerges through acts of speech or wri ing it is always capable of reinterpretation. ${ }^{11}$ Such a view provides seemingly irresistible force to $\vec{Q}_{a}$ radical scepticism capable of denying any claim to truth. By its own account it cannot claim truth even for itself. The metanarratives that hitherto 
sustained belief, as Francois Lyotard boldly declares, become incredible. ${ }^{12}$ We are left with the legitimation crisis of postmodernity. ${ }^{13}$

The postmodern world is one of plurality and diversity, full of voices clamouring allegedly with equal justification, if not equal power, to be heard. The authority of the nation state declines in an age of global politics and instant communication. International corporations slyly exploit the desires of the consumer. With the aid of panoptic autosurveillance, power itself abandons repression in favour of seduction. ${ }^{14}$ Knowledge becomes information, commodified and sold in bits and bytes, not in order to enlighten but to enhance performativity. Art implodes into endlessly reproducible retro, and it becomes impossible to differentiate the real from the simulated. It is not surprising that some feel we are entering the hyperreal, nihilistic nightmare of the contemporary America evoked by Baudrillard, ${ }^{14}$ regarded by many as the the high priest of postmodernity. In contrast, others bask in the jouissance of emancipation from the cruel grip of rationalist discourse. To yet others, these are merely the empty, self-indulgent intellectual contortions of an elite who choose to ignore the persistent plight of women, the poor and downtrodden.

The question is, how do we choose which vision to espouse?

Which brings me back to value, and thence to Marion, a hypertensive patient.

\section{The problem of value}

How do we decide what is valuable? The problem seems to me to be existential, moral, epistemological, and metaphysical. Existentially, value contributes meaning to life. Morally, value is judged in the light of what is good or better, and charges that we address the tension between the individual and the social good. Epistemologically, value is related to knowledge and truthfulness, which in turn seems to demand a quest for metaphysical foundation. All are threatened by a postmodern perspective.

Like others, I suspect, the older I become the more I require my life and work to be meaningful, but at the same time the more I find myself questioning its meaning. To be meaning-full, my work must have value for others. I do not mean simply that I could do anything as long as someone agrees to pay me. My work must have a value, not just a price, and this means that it should matter were I not there to do the job that I, personally, do.

When it comes to the practice of medicine, therefore, what is it that matters? As part of a socially constructed machine I am one of many, operating more or less efficiently to further the medical endeavour. But I also act as an individual. Which is more important? If I accept that I operate within the medical machine, indeed, that I am in some sense operated by it, then I sacrifice autonomy to function. I may yet gain a sense of personal value if I believe in the moral value and efficacy of medical practice as a whole. If, however, I believe that my value inheres in my individuality, then I must take responsibility for and be confident of my motives and competence. I think it probable, and arguably desirable, that I contribute something of value in both senses. It is not an all-or-nothing thing. But it is possible, I suppose, that my contribution may have no value after all.

I would, of course, prefer my presence to matter. And I would like to believe, and others to believe also, that I do more good than harm. But even if so, what of this belief? Can we be satisfied with an idea of value which depends merely on subjective, or even collective, judgment? Should not value be independent of a point of view, like the idea of absolute truth or goodness, or certain knowledge? Or have such foundationalist yearnings been effectively scuppered by postmodern doubt?

\section{Nomothetic and idiographic perspectives}

Marion's situation is a useful one to think about. There is nothing so urgent or critical about her case that she demands urgent and uncontroversial medical aid. She has moderate hypertension, established according to criteria set by the working party of the British Hypertension Society. They base their recommendations on a metaanalysis of several scientific studies of hypertension and its treatment which indicate that her risk of stroke might be reduced by as much as half if she is adequately treated. Today, the doctor's recording of her blood pressure lies within normal limits. Doctor and patient seem to get on well; Marion leaves satisfied, and will continue taking her medication regularly. The doctor too is happy. By reducing the risk of stroke Marion not only gains the prospect of a longer life, but the overall burden of future healthcare, a cost to the nation, may be lessened also.

There are well established lines along which such a cosy view might be deconstructed. I have considered my own worth in terms of a tension between my value as a person, and the value of my performance of a social function. There is a parallel tension in this consultation which occurs at the intersection of two axes. On the one hand there is the nomothetic, founded on statistical medical knowledge and providing the basis for law-giving, and on the other, the idiographic, mapping what is 
idiosyncratic and individual. The first axis takes Marion to be a case of mild hypertension. She satisfies agreed diagnostic criteria and is expected to behave and respond as if she were an example of a statistically generated ideal type. Medical opinion has taken this view on the evidence of scientifically conducted clinical trials. What makes Marion, and all the other subjects of such trials, an individual person is temporarily bracketed. The assumption is made that the knowledge gained can be applied to the treatment of individual hypertensive patients whoever and wherever they might be.

\section{The nomothetic perspective: measure and manage}

The nomothetic perspective, by discerning and defining clinical parameters, to be recorded and increasingly computerised, provides information that can be used, amongst other things, for health planning. All that is required is that doctors follow guidelines or operate protocols for diagnosing, treating and monitoring mild hypertension. With the cooperation of patients, the beneficial results seen in the trials will then become manifest nationwide. Everyone is a winner. But the use of such information tends to exert an insidious normative pressure. It promotes an attitude which sorts individuals into kinds, and then prescribes medical management of the kind rather than the individual. Such pressure has the potential to become a stranglehold in which the individual perspective is lost. That risk is compounded the more such information escapes the boundaries of clinical confidentiality and becomes conditional for the underwriting of medical or life insurance.

When nomothetic knowledge is put to work "the cooperation of patients" becomes a pivotal phrase; and one should add, equally importantly, "the cooperation of doctors". Here enters the idiographic. What makes each individual patient more or less likely to be at risk, to comply with and respond to treatment? What makes doctors more or less likely to adhere to guidelines and protocols, perhaps at the cost of clinical freedom? Before I return to the idiographic, it is worth considering some intrinsic problems of a nomothetic approach. First of all, it demands validation. Not only must we be satisfied that knowledge gained from clinical trials is valid in scientific terms, we must also be satisfied that these terms themselves are sufficient guarantors of truth. The scientific method, however rigorously applied, is after all only a method and yields only a certain kind of knowledge. It cannot in itself guarantee certain knowledge immune to scepticism. Furthermore, some would argue that bracketing the personal order to conduct a trial misses precisely what important, and little knowledge of real value gained as a consequence.

Finally, who is in a position to judge the validif or otherwise of scientific knowledge? Certain $\$$ not most of our patients. Scientific knowledge becoming increasingly specialised; the preserve of experts. Most people live their lives bypassing this knowledge altogether. Scientific medicine, imper fectly represented via the go-between of popula media, often appears to the consumer of health generate as many dangers as benefits. The truts claims of medicine are only of real concern to the patient in the context of a current clinical transa tion. It could be said, therefore, that in a practica sense at least, the truthfulness of such knowledge depends on who believes it, and the power witi which it is invested. To adopt a Foucauldian atto tude, knowledge is power and power is truth. The metanarrative of medicine - the possibility of scot entifically guided progress towards better heal through medical practice - is not so much incres ible as irrelevant.

\section{The idiographic perspective: fear and} desire If, in a postmodern world, the voice of the consumer is gaining authority, and credulin towards metanarratives really is on the wane, the nomothetic would also be expected to lose powe? Under such circumstances the resistance to normative pressures might be expected to stiffer. The axis of importance intersecting with the idiographic now becomes that along which desi and fear can be manipulated. The doctor becomes less a law-giver, more a salesman. In order to retain a sense of value in her work, she must maintain belief in her product even in the face of mounting incredulity. Her word ceases to be law; she must persuade rather than legislate, an persuasion, if it is to be effective, must harness fe or desire. Marion must be persuaded that tho morbidity associated with being diagnosed and treated is worth it in the long term; a task whiab her doctor may find more pressing if she 15 charged at the same time with reducing the incidence of stroke in society as a whole.

The idiographic takes an objective but intimate view of the individual, recognising the individualis subjectivity. It is objective, in Thomas Nage sense of objectivity, ${ }^{15}$ within limits that accomm \& date the tension between an internal and an exte $\vec{g}$ nal view. It takes account not only of individuad risk, physical characteristics and responses, understood from outside as it were, but also of inner 
feelings and reasons for thinking and behaving in one way rather than another. In terms of persuasion, then, what is crucial is an awareness of the twin spurs to action, fear and desire. Marion might comply with her medication purely out of the fear that should she stop some dreadful consequence would ensue. Her doctor might then be tempted towards intimidation, however subtle, as a method of persuasion. If so, could she really be content? The health of the nation might benefit by one stroke fewer, but the doctor might think that living in fear rests somewhat at odds with living healthily.

What can Marion's doctor do to assuage her fears and yet secure compliance? A common temptation is to believe that the answer lies in educating the patient. Given the "facts" in a way that she can understand, Marion would surely make the rational choice to comply with her treatment. There are at least three difficulties here. To begin with, Marion might rationally decide to accept the risks of not taking treatment, arguably bringing into opposition the values of autonomy and the greater good. Secondly, "facts" become rather elusive things when viewed through sceptical, postmodern lenses. Last, but not least, belief, in itself, does not propel us into action. To modify Hume's dictum action, if not reason, is the "slave of the passions". We need the spur of fear or desire. Having doubts about the exploitation of fear as a healthy option, what of desire?

If the spur to Marion's compliance is not to be fear, perhaps of an untimely death, what is it that she might desire, and how might her doctor influence her? She could, maybe, tell Marion that taking the treatment will increase her chance of more life, if not necessarily better life. That, however, seems unlikely to make Marion desire life more. Perhaps she might simply seek to reassure Marion and, by relieving anxiety, thereby at least liberate desire. Problems arise for the doctor, however, if her confidence in that reassurance is insecure beyond any doubts of personal competence because the status and validity of medical knowledge is itself held in doubt by Marion, or the media, or the doctor herself. There is little value in false reassurance.

Another answer might be sought, at least in part, in the emotional quality of the consultation; within the doctor-patient relationship. Both smiled, both were satisfied with the encounter, and one can imagine Marion leaving with a lightened step and a greater appetite for the day ahead; desire, like energy, the product of their interreaction. But suppose the actions of either or both are motivated or, even worse, determined by unconscious processes, as psychoanalysis might have us believe. The quality of interaction itself becomes suspect if a bright surface conceals a dark interior. An overdependent relationship might induce compliance out of a desire to please, or out of the fear of rejection. In any case, the mutual gratification of their interaction is not, on its own, sufficient guarantee of the overall value of the consultation, for if it were, any medical value would become, at best, fortuitous.

\section{The rise of the consumer}

Much of human activity occurs as part of common social practice, routinely and habitually, with a sense of self somewhat redundantly attached. Fear and desire make us truly alive. In the face of immediate danger fear rather than desire is the more valuable spur to action. In other situations, possibly Marion's, acting from desire might be preferred. Desire emerges between the self and other; between the social and the individual. As with fear, through desire we are propelled into action, into life. And when desire meets its object, in that moment, life is enhanced. Experience tells us, regrettably, that the moment fades more or less rapidly. This may be just as well for modern capitalism dependent on the seduction of consumers with endlessly re-invented objects of desire. But for the consumer herself, however life-enhancing, there is no guarantee that desire's conjunction with its object is without danger. One only has to think of alcohol, cigarettes and AIDS. Nor is there any necessity that value inheres in an action just because it is an act of desire. It is possible to desire evil as well as good, harm as well as healing, the good of oneself at the cost of the good of others, or vice versa.

Consumerism lionizes personal choice, and raises the expectation that desires can and will be satisfied. The commodification of health, the promotion of a free market of healthcare, coupled with a decline in public faith in the biomedical metanarrative, means that consumers of health will increasingly seek diverse health products. When "shopping" within mainstream medicine the exercise of choice in the kind, quality, timing and content of healthcare provision becomes no less an expectation. Should the expectations of patients, qua consumers, conflict with sound medical advice, allowing there to be such a thing, something has to give. If the maxim "the customer is always right" applies, either the doctor-patient relationship is threatened, or good medical practice compromised. Value is likely to be a casualty in both instances. 


\section{Rabbits out of hats}

There is much in postmodern philosophy and sociology which, if nothing else, appeals to a common attraction towards anything capable of undermining the established view of things. But in going beyond mere scepticism, it may sometimes represent a more destructive iconoclasm which seeks to undermine any basis for belief. The danger is then a tendency towards amoral relativism. If a sense of value is to be retained in any aspect of our lives then, I believe, this latter tendency is better avoided. And yet what other popularly held philosophy offers a more satisfactory foundation upon which to build a sustainable morality? Naturalism and scientific realism, unless rescued by God's will, in offering explanation risk reducing human behaviour to amoral laws of nature devoid of meaning. Idealist morality, on the other hand, would seem to depend on transcendental entities which ultimately elude non-circular definition. Liberal or communitarian morality likewise depend on apparently straightforward, but in the final analysis metaphysical, concepts such as self and community.

The legacy of the Cartesian proclamation of certain knowledge tends to infuse all such approaches with a belief in the necessity of securing foundations. A yearning which postmodernists might hold in contempt; a yearning which a pragmatist like Richard Rorty would regard as hopelessly misconceived and therefore best abandoned. ${ }^{16}$ But can we happily accept that there is no absolute truth, merely a plurality of views of the world, each adopted in the context of a mutually supporting web of beliefs held in common by a community and thereby constitutive of local and contingent truths? Such a non-foundational view apparently does not preclude the possibility of arguing, defining and agreeing moral codes of conduct, or establishing acceptable conditions of evidence for what should be taken to be facts. It simply means that we cannot appeal to a higher court for a final judgment should we disagree. Personally, I am not sure if this view, whilst seeming to avoid many a pitfall, is capable of sustaining a truly satisfying account of value. In the end it seems somewhat question-begging. But where else might a more satisfying account be found?

\section{Worthwhile job}

In this essay I have questioned the basis of the value of my work as a GP, and in particular the value of the consultation between Marion and her doctor. Somewhat regretfully, it seems that I must abandon the hope of basing that value on secure foundations. Yet I am not prepared to discredit the undoubted sense of value that I do feel, and feet often enough to sustain my belief that, at leaș most of the time, I am doing a worthwhile job. have emphasised the familiar tension between the individual and social good and the danger of treating Marion as a case and not as a persor Where values compete they risk being diminishe if not lost altogether. Appeal to the facts of evidence in support of our efforts to manage hep case must allow that we are not dealing with abso $\vec{\theta}$ lutes. Today's fact can turn out to be tomorrow's error. Facts in any case are increasingly the preserve of experts and what counts as true, i terms of constituting belief, often depends of issues of power rather than truthfulness. Should Marion assert a different point of view, or as $a \vec{n}$ empowered consumer make what seems to us af unreasonable demand, we must now be wary of dismissing it simply because it contradicts received medical wisdom.

\section{Right action}

If the facts of the case cannot be depended on supply value, no more can we safely assume this because the consultation seemed to go well it personal level that it was ipso facto valuabile Unconscious motives or psychodynamic facti can undermine the most agreeable of exchange\&. Nor can we, accepting that reason alone does no move us, make appeal to which spur to action, fear or desire, it is that propels us into activity. Belie can be wrong, and actions prompted by fear or desire may equally turn out well or ill.

When all is said and done, in the search for value I am compelled to resort to the persona sense of value I experience in the doing of a corf sultation. Value emerges within the experience off doing. It does not, as such, depend on the suppof of theory, or the application of a formula, although both may be utilised. Nor does it primarily, I have to confess, lie in the pious hope of contributing the Health of the Nation. It lies in the apperception of right action, like a Heideggerian carpentep who, finding his hammer ready-to-hand, ${ }^{17}$ uses hig practical skill and knowledge to knock the nail if straight and true, securing his timber as intended. I think that when I consult at my best, my know edge and medical skills are, like the carpenter hammer, ready to hand; tools to accomplish a task whose particular contour only emerges withing and does not pre-exist to be imposed upon, the interaction with my patient. In that sense patie and I are more like treecutters who, to adopt Gadamer's analogy, ${ }^{18}$ both wishing to fell a tres, take up a two-handled saw and wield it with a mutual and harmonious rhythm. If accomplished 
successfully, such tasks form the basis of practice - in Alasdair MacIntyre's sense of the word, ${ }^{19}$ a coherent and complex form of cooperative human activity realising goods which are internal to that activity.

There are, I realise, problems with this conclusion. For instance, what status has the value of a consultation which feels just right at the time, but in the light of later evidence appears to have resulted in unwanted consequences? This argument, however, could apply to any medical intervention viewed in retrospect. What of the consultation that felt wrong, but later appears to have been for the best after all? In reply one need only ask, how long is after all. Is it ever possible finally and definitively to arbitrate on the value of a consultation? The proof of the pudding is in the eating; not in the subsequent indigestion or hypercholesterolaemia, or even the prevention of malnutrition.

I do not, of course, wish to deny rationality or reason a place in this debate, or science either. Much judicious care must be taken in the acquiring of medical knowledge and skills. But knowledge and skill are not in themselves what confer value on a consultation. It is the authentic, sincere application of these in each unique context, in awe and respect of the difference between self and other, that provides the basis for value. There is no rational justification for demanding more of the concept of value than this. Any reasoned argument can be reasonably argued against. And should we deny authenticity its part, we have failed to rescue value and find ourselves confronted with an unavoidable nihilism.
Sam Smith is a General Practitioner.

\section{References}

1 MacNaughton J. Anecdotes and empiricism. British fournal of General Practice 1995;45: 571-2.

2 Romanyshyn RD. Psychological life: from science to metaphor. Milton Keynes: Open University Press, 1982: 24-6.

3 Keats J. Lamia. In: Lyon D. Postmodernity. Buckingham: Open University Press, 1994: 34.

4 Smith GB. Nietzsche, Heidegger and the transition to Postmodernity. Chicago, London: University of Chicago Press, 1996: 82-3.

5 Khun TS. The structure of scientific revolutions [2nd ed, enlarged]. Chicago, London: University of Chicago Press, 1970.

6 Rabinow P, ed. The Foucault reader. Harmondsworth: Penguin Books, 1986: 51-75.

7 Friedson E. Profession of medicine. New York: Dodd, Mead \& Co, 1975.

8 Mckeown T. The role of medicine: dream, mirage or nemesis? London: The Nuffield Provincial Hospitals Trust, 1976.

9 Illich I. Medical nemesis. London: Caldar Boyars, 1974.

10 Rorty R. Wittgenstein, Heidegger, and the reification of language. In: Rorty R. Essays on Heidegger and others. Philosophical papers, vol 2. Cambridge: Cambridge University Press, 1992: 50-65.

11 Matthews E. Twentieth century French philosophy. Oxford, New York: Oxford University Press, 1996:157-86.

12 Lyotard J-F. The postmodern condition: a report on knowledge. Manchester: Manchester University Press, 1984.

13 Lechte J. Fifty key contemporary thinkers. London, New York: Routledge, 1994: 233-7.

14 Bauman Z. Intimations of Postmodernity. London, New York: Routledge, 1992.

15 Nagel T. The View from nowhere. Oxford, New York: Oxford University Press, 1986: 4-6.

16 Rorty R. Philosophy and the mirror of nature. Princeton, NJ: Princeton University Press, 1979.

17 Dostal RJ. Time and phenomenology in Husserl and Heidegger. In: Guignon C, ed. The Cambridge companion to Heidegger. Cambridge: Cambridge University Press, 1993: 141-69.

18 Gadamer H-G. The enigma of health. Cambridge: Polity Press, 1996: 38.

19 Mulhall S, Swift A. Liberals and communitarians. Cambridge, USA, Oxford: Blackwell, 1992: 82-6. 